NASA Technical Memorandum 109118

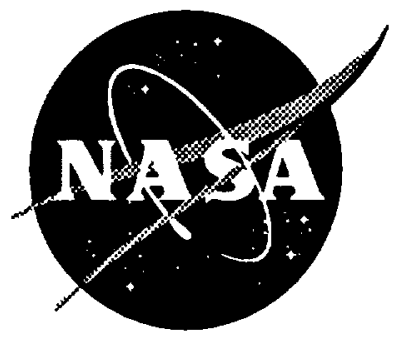

\title{
Evaluation of Several Non-reflecting Computational Boundary Conditions for Duct Acoustics
}

Willie R. Watson and William E. Zorumzki

Langley Research Center, Hampton, Virginia

Steve L. Hodge

Virginia Consortium of Engineering and Science Universities, Hampton, Virginia

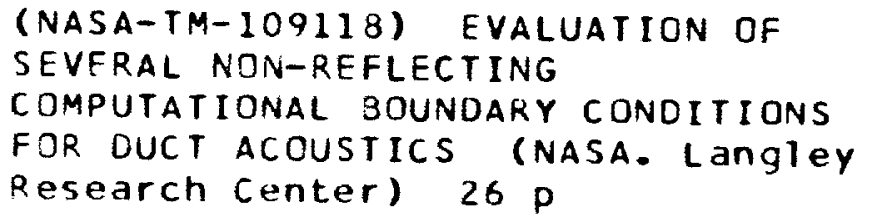

May 1994

National Aeronautics and Space Administration Langley Research Center Hampton, Virginia 23681-0001 



\title{
Evaluation of Several Non-reflecting Computational Boundary Conditions for Duct Acoustics
}

\author{
Willie R. Walson and William E. Zorumski \\ NASA Langlry Researh C'rulrt, Ilamplon Viryinia 23666 \\ Steve I,. Hodge \\ Virginia Consortium of Enyincering and S'cience Unincrsities, Iampton Virginia 23666
}

\begin{abstract}
Several non-reflecting compulational boumelary conditions that meet certain criteria and have potential applications to duct aroustics are evaluated for their effectiveness. The same interior solution scheme, grid, and order of approximation are used to evaluate each condition. Sparse matrix solution techuigues are applicel to solve the malrix equation resulting from the discretization. Modal series solutions for the sound attemuation in an infinite duct are used to evaluate the accuracy of each non-reflecting boundary condition. The evaluations are performed for sound propagalion in a softwall duct, for several sources, sound frequencies, and duct lengths. It is shown that a recently developed nonlocal boundary condition leads to sound attenuation predictions considerahly more accurate than the local ones considered. Results also show that this condition is more accurate for short ducts. This leads to a substantial reduction in the mumber of grid points when compared to other non-reflecting conditions.
\end{abstract}

\section{Introduction}

Over the past decade, there has been considerable interest in the use of computational methods for oblaining solutions to problens in arroacoustics. This interest stems primarily from a lack of exact analytical solutions for predicting, understanding, and controlling various acoustic phenomena. As compulational models have evolved, difficulty with the closure of the computational domain has emerged as a major problem in the calculations.

'The difficulty with closure of the computational domain arises because aeroaconstics problems are typically set in an infinit. domain with a radiation condition on the boundary surface at infinity. However the computational clomain cannot extend to infinity, so the problem is decomposed into a finile computational domain within some outer domain that extends to the boundary at inlinity. 'Tlo inlerface between lhese domains is called the artificial or computational boundary. One needs a set of equations valid at this computational 
boundary. The primary purposes of these equations is to guarantee a unique and well-see posed solution to the aeroacoustics problem. These equations are usually a set of partial differential operators whose terms involve only local information at each boundary point such as the dependent variables and their derivatives. 'To avoid nonphysical reflections from occurring at the computational boundary, these differential operators are also intended to constrain the local solution to consist of waves traveling outward from the computational domain. When used in this manner, the differential equations are called local non-reflecting boundary conditions.

There currently exist a large number of rescarch papers concerned with the development of local non-reflecting conditions for use at computational boundaries (refs. [1]- [6]). The references cited above represent only a small sampling of local boundary conditions, which have potential application to duct acoustics. Unfortunately, experiences show that the conditions developed in these works are reflecting for a large class of aerocoustic problems. This is especially true for classes of acroacoustic problems for which waves impinging on the computational boundary is not close to momal incidence.

The proper approach to dealing with the problem of finite computational domains is to match the computational solution in the inner domain with the general solution in the outer domain. This general outer solulion satisfies the radiation condition at infinity and constrains the solution on the computational interface. But this constraint is not in general a local condition. Instead, a given value of a variable at one point on the interface surface influences the values of other variables at all points on the interface surface. Constraints of this type are call nonlocal conditions. They can be constructed for all classes of problems in which the exterior domain is linear.

In a recent report (ref. [i]), the authors presented the formulation of a nonlocal nonreflecting boundary condition for duct acoustics. The purpose of this paper is to compare this nonlocal boundary condition to several local conditions that could compete with it. Due to space limitation and time rest,raints, all of the existing non-reflecting boundary conditions could not be compared with this new condition. 'T'o limit the number of choices, we include only those conditions that meet cortain critoria.

Section 2 defines the basic equations used in the computation and presents the nonreflecting boundary conditions that are tested. Modal series solutions for the sound attenuation in an infinite duct are used to evaluate the accuracy of each boundary condition. This series solution is also presented in section 2. 'The interior solution technique, method of implementing each boundary condition, effect of each condition on the matrix structure, and matrix solution technicque is described in section 3. Results for a broad range of acoustic parameters are presented in section 4. Conclusions, relative to boundary conditions evalu- 
ated in this paper are given in section 5. References and figures cited in this report are given at the end of section 5 .

\section{Governing Equations and Boundary Conditions}

Consider a two-dimensional rectangular duct without mean flow as shown in figure 1. The duct is assumed infinitely long in the axial dircetion with a known acoustic source pressure at the plane $x=0$. The walls of the duct contain sound absorbing material whose material properties vary along the axis of the duct for $0 \leq x \leq L$. Sound absorbing properties of the wall lining are specified by perscribing the admittance of the lower wall, $\beta_{0}(x)$, and upper wall, $\beta_{H}(x)$, of the duct. Within the region $l<r \leq \infty$ the material properties of the liner are assumed uniform, so that an outgoing wave ficld exists in this region. It is the purpose of this work to test several non-reflecting boundary conditions for terminating the duct at $x=L$.

Steady-State acoustic wave solutions within the duct in figure 1 , take the form

$$
\tilde{p}(x, y, t)=\eta(x, y) e^{i 2 \pi s t}
$$

where $\tilde{p}$ is the steady state acoustic pressure, $f$ is the frequency in Hertz, $i=\sqrt{-1}$, and $p(x, y)$ satisfies Helmholtz's equation

$$
\nabla^{2} p+k^{2} p=0
$$

Here, $k=\frac{2 \pi /}{c}$ is the fresspace wavermmber, $r$ is the sound specel and $\nabla^{2}$ is the Laplace operator in the $(x, y)$ plane.

The inflow and wall boundary conditions reguire a specification of the source pressure and wall admittance

$$
\begin{gathered}
p(0, y)=C(y) \\
\frac{\partial p}{\partial y}(r, 0)=-i k \cdot \beta_{o}(x) p(x, 0) \\
\frac{\partial p}{\partial y}(0, I I)=i k \cdot \beta_{I I}(x) p(x, I I)
\end{gathered}
$$

where $G(y), \beta_{0}(x)$, and $\beta_{I I}(x)$ denote the known source pressure and normalized admittance of the lower and upper wall respectively. To complete the sperification of the boundary value problem in the duct, a non-reflecting condilion must be specified at the outflow boundary.

Several non-reflecting boundary conditions were considered for application at $x=L$. In order to limit the number of choices only those boundary conditions that met the following criteria were considered 
1. The boundary condition must have a frepuency and possibly time domain extension.

2. The boundary condition must be extendible to shearing flows and three dimensionality.

3. The order of the boundary condition must be such that the linear finite element theory of ref. [7] could be appliced for the interior solution.

4. The coupling of the boundary condition with the interior solution scheme must lead to a coefficient matrix that remains block tridigonal.

The non-reflecting conditions that mext the above criteria that are tested in this paper are

1. The local boundary condition of Giles (rof. [5])

$$
\frac{1}{c} \frac{\partial j}{\partial t}+\frac{\partial j}{\partial x}=0
$$

2. The nonlocal frecpuency-domain boundary condition of the current authors (ref. [7])

$$
\left\{p_{i}\right\}=\left[Z_{i j}\right]\left\{u_{j}\right\}
$$

where $\left\{p_{i}\right\},\left\{u_{j}\right\}$ are vectors conlaining values of the frequency-rlomain acoustic pressure and normal velocity at boundary node $i$ and $j$ respectively. Further, the coefficients in the nodal impedance matrix $\left[Z_{i j}\right]$ are defined explicitly in ref. [7].

3. The local highly-absorbing boundary condition of Engquist and Majda (ref. [1])

$$
-\frac{1}{e^{2}} \frac{\partial^{2} j}{\partial l^{2}}-\frac{1}{c} \frac{\partial^{2} j}{\partial x \partial t}+\frac{1}{2} \frac{\partial^{2} \dot{p}}{\partial y^{2}}=0
$$

Several remarks concerning the aloove boundary conditions are in order. Each of the above boundary conditions has bern specialized to both a no-flow environment and right moving waves. All of the above conditions are non-preflecting for plane wave sources. The first nou-reflecting condition above is a familiar onc that was derived by lledstrom (ref. [2]) and several others prior to the work of (iiles. 'This condition has been used by duct acousticians for several decades as a termination condition, and is often referred to as the $\rho c$ termination condition. Becanse the Giles condition (rof. [5]) in the absence of mean flow reduces to this condition, it is referrel to here as the "Giles condition." Finally, Engquist and Majda ((ref. [1]) have shown that the third condition gives reflections considerably smaller than the first condition when the Neumann wall boundary condition is imposed. This conclusion may not be valid when the sound propagates between walls lined with sound absorbing material. 
Periodic acoustic fields determined from the non-reflecting boundary conditions above are used to evaluate the performance of the wall lining over $x$ length of linings. The following expression is used to evaluate the acoustic inkensity at a point $(x, y)$ in the duct ref. ([8])

$$
\left.I(x, y)=\frac{1}{4 \pi \int \rho_{0}} \Re\left\{p(x, y)\left[i \frac{\partial p(x, y)}{\partial x}\right)\right]^{*}\right\}
$$

where the superscript asterisk denotes the complex conjugate, $\rho_{0}$ is the mean density within the duct, and $\Re(\}$ denotes the real part of the complex expression within the braces. The attemation over $x$ length of lining in decibels is

$$
\begin{aligned}
& d B(x)=10 \log _{10} \frac{W(0)}{W(x)} \\
& W(x)=\int_{0}^{I I} I(x, y) d y
\end{aligned}
$$

Modal series solutions for the attenuation are used to determine the accuracy of each non-reflecting boundary condition. These series solutions are possible when the material properties of the wall lining are constant. When this condition is met, the solutions to Helinholtz's equation in the form of outgoing waves are of the complex exponential form

$$
\tilde{p}(x, y)=\sum_{m=1}^{M} A_{m} P_{m}(y) e^{i \kappa_{m} x}
$$

where $K_{m}$ is the axial propagation constant, and the functions $P_{m}(y)$ are the acoustic pressure eigenfunctions. Note that the series has been truncated at a finite number $M$. To insure no reflections, the sum in equation (12) is taken only over modes whose axial propagation constants possess positive imaginary parts. 'The method for obtaining $P_{m}$ and $K_{m}$ is described in ref. [7] and the mole amplitude coeflicients are obtained from the source condition and the orthogonality of the lined duct modes

$$
A_{m}=\frac{\int_{0}^{\prime \prime}\left(,(y) I_{m}^{\prime}(y) d y\right.}{\int_{0}^{\prime \prime} I_{m}^{\prime 2}(y) d y}
$$

Fquations (12) and (13) are substiluted inlo cquations (9)-(11) to obtain the modal series expression for the attemuation of the lining.

\section{The Numerical Method}

In this section of the paper we describe the interior solution technique, the numerical implementation of each of the non- reflecting boundary conditions, and the matrix solution techuique. Several details liave been purposely omitled since they can be obtained in several of the cited references. 


\subsection{The Interior Solution Technique}

The numerical method chosen to solve equation 2 coupled with the source, wall and nonreflecting boundary conditions is a Galerkin Finite Element Method with linear elements used as the basis functions. The method is described in detail in the earlier paper (ref. [7]). Application of the method results in a matrix equation of the form

$$
[A]\{\Phi\}=\{r\}
$$

where $[A]$ is an $M N x M N$ complex matrix, and $\{\Phi\}$ is a $M N x 1$ column vector containing the nodal values of the unknown acoustic pressure. The integers $N$ and $M$ are the number of grid points in the $x$ and $y$ direction respectively. Equation (14) does not contain the effects of the non-reflecting condition. The non-reflecting condition must be imposed on this matrix equation before the solution can be obtained. Details of the implementation of each non-reflecting boundary condition are now discussed.

\subsection{Boundary Condition Implementation}

The frequency-domain form of the Giles condition ref. [5] is

$$
k p(L, y)-i \frac{\partial p(L, y)}{\partial x}=0
$$

The Giles condition is discretized as followed

$$
k p_{N, j}-i \frac{\left[p_{N, j}-p_{N-1, j}\right]}{\left(x_{N}-x_{N-1}\right)}=0, \quad j=1,2 \ldots M
$$

Note that the spatial gradient in the boundary condition discretization is only first order accurate. Thus, the interior solution and boundary condition discretization are of the same order. Equation 16 constitutes $M$ equations which are imposed as restraints on equation 14 prior to solving the matrix erpuation.

Boundary condition implementalion of the nonlocal condition is exactly as discussed in ref. [7]. The axial velocity vector at the grid points $\left\{u_{j}\right\}$ is expressed in terms of the gradient of the acoustic pressure ficld. The axial acoustic pressure gradient is then discretized with a first order difference approximation. This results in $M$ restraint equations which are imposed on the matrix equation in the usual manner.

The frequency-domain form of the Bingquist and Majda condition ref. [1] is

$$
k^{2} p(L, y)-i k \frac{\partial p(L, y)}{\partial x}+\frac{1}{2} \frac{\partial^{2} p(L, y)}{\partial y^{2}}=0
$$


For the numerical experiment presented here, the above equation is discretized using first order one-side differences

$$
\begin{gathered}
k^{2} p_{N, j}-i k \frac{\left[p_{N, j}-p_{N-1, j}\right]}{\left(x_{N}-x_{N-1}\right)}+\frac{\left[p_{N, j+2}-2 p_{N, j+1}+p_{N, j}\right]}{2\left(y_{j+1}-y_{j}\right)^{2}}=0, \quad j=1,2 \ldots M-2 \\
k^{2} p_{N, j}-i k \frac{\left[p_{N, j}-p_{N-1, j}\right]}{\left(x_{N}-x_{N-1}\right)}+\frac{\left[p_{N, j-2}-2 p_{N, j-1}+p_{N, j}\right]}{2\left(y_{j}-y_{j-1}\right)^{2}}=0, j=M-1, M
\end{gathered}
$$

Note that although the boundary condition has a second derivative term in $y$, first order onesided differences are still used to approximale all derivatives in $x$ and $y$. The $M$ equations generated by the discretization aboved are imposed on the matrix equation (14) as a set of restraints.

\subsection{Effects of Boundary conditions on the Matrix Structure}

The augmented global matrix generated by Galerkin's Method, following application of the source, wall, and non-reflecting boundary conditions, is an unsymmetric, positive indefinite, complex matrix. Fortunately, owing to the discretization scheme and choice of non-reflecting boundary conditions, it will be block tridiagonal as shown in figure 2 . The superscript $T$ denotes the matrix transpose in the figure. Fach minor block $A_{I}$ and $B_{I}$ are $M x M$ matrices that are tridiagonal. These blocks are obtained from the interior solution scheme and wall boundary conditions. The minor block $E_{1}$ is the identity matrix, which results from applying the source condition (3). Minor blocks $C_{N}$ and $D_{N}$ are $M x M$ complex matrices that contain the effects of the non-reflecting conditions. liach minor block $C_{N}$ and $D_{N}$ is a diagonal matrix when the Giles condition (16) is implemented. Application of the Engquist and Majda condition (18) and (19) leads to a diagonal minor block $C_{N}$, while $D_{N}$ will contain a main diagonal, two superdiagonal, and two subdiagonals. Finally, both minor blocks are full matrices when the nonlocal condition of Zormmski, Wat.son, and IIodge (7) is implemented.

\subsection{Solution to the Matrix Equation}

The matrix $[A]$, generated by the melliod describerl here, is not symmetric or positive definite. Fortunately, it is block tridiagonal as shown in figure 2. Much practical importance arises from this structure, as it is convenicut for minimizing storage and maximizing computational efficiency. Econoniy of storage is acheived by storing the rectangular array of coefficients within the bandwidth of $[A]$ as shown in ligure 3. All computation, storage and boundary condition implementation is performed only on the rectangular portion of this matrix. Special Inatrix techniques exist, for a solution of this structure. Gaussian climination with partial pivoting and equivalent, row inlinity norm scaling is used to reduce the rectangular system to 
upper triangular form. Back substitution is then used to obtain the solution for the acoustic pressure.

\section{Results and Discussion}

$\Lambda$ computer code implementing all three boundary conditions and the modal series solution discussed in this paper has been developed and programmed to run on a supercomputer. The results were obtained with the underlying objective of comparing the attenuation obtained from each boundary condition with the modal series solutions over a broad range of acoustic parameters. The same interior solution sclıeme, grid, and order of approximation are used to evaluate each non-reflecting condition. Within this context, the effect of changing the source pressure, frequency and duct length is evaluated for a specified lining.

With respect to the acoustic parameters, effects of three source pressures on the boundary condition are studied (see eq. 12)

$$
\begin{gathered}
G(y)=P_{1}(y) \\
G(y)=P_{5}(y) \\
G(y)=\sum_{m=1}^{10} m^{2} P_{m}(y)
\end{gathered}
$$

Other parameters include a softwall duct with $\left(\beta_{0}=\beta_{H}=.5-.5 i\right)$, three frequencies $(f=100 \mathrm{~Hz}, f=1,000 \mathrm{~Hz}, f=5,000 \mathrm{~Hz})$ and four duct lengths $(I=H, L=.8 H, L=$ $.6 I I, L=.2 I I)$. All calculations were performed for a duct 1 meter high $(H=1 \mathrm{~m})$ and at ambient conditions $(c=343 \mathrm{~m} / \mathrm{scc})$. The griding remained fixed as each acoustic parameter was changed. Fifty-one evenly spaced points were used in the $y$ direction $(M=51)$ and the number of axial points $N$ was determined such that 10 points per axial wavelength were retained at the highest frequency of $5,000 \mathrm{ll} z$.

Figure 4 compares the attenualions predicted from the boundary conditions when the loration of the boundary is at $L=I J$. The source is the lowest order mode and the frequency is $100 \mathrm{II} z$. The new nonlocal condition give predictions that are in excellent agreement with the modal series. Giles's condition is more accurate than the condition of Engquist and Majela for $\frac{x}{L}<.65$, and in the region $\frac{x}{l}>$.65) the condition of Engquist and Majda is more accurate. All curves except thal of lingquist and Majda show a linear attenuation rate, as expected for a single mode source. The oscillations in the attenuations predicted by the Engquist and Majda condition are typical of results obtained when the boundary is reflecting. Figures 5,6 and 7 show resulls for the same source and frequency, but when the boundary is located at $x=.8 I, x=.6 I$, and $x=.2 H$, respectively. Although the attemuations are lower due to the shorter duct length, the trends are consistent with those 
of ligure 4. Note also that, as the boundary is brought closer to the source, the attenuation on a percentage basis is less accurate for all conditions except the nonlocal condition.

Attenuation predictions in figure 8 , for which $L=I$ and the frequency is $1,000 \mathrm{~Hz}$ are typical of results obtained for several other duct lengths at that frequency. Here, the source is still the lowest order mode. At this higher frequency the liner is not effective, giving little attenuation over the lining. Both the Giles and the nonlocal condition gives accurate predictions but the condition of Engquist and Majda gives poor comparison with the modal series. Results were also computed for $5,000 \mathrm{IIz}$ with the lowest order mode as the source and for several duct lengths. 'T'he attenuation curves are not shown in order to limit the amount of discussion. However, trends were consistent with that of figure 8 .

Figure 9 shows results at a frequency of $100 \mathrm{II} z, L=I I$, and for the fifth order mode source. All boundary conditions give good predictions for $x / L<.75$. However, the condition of Engquist and Majda and also that of (iiles gives poor attenuation predictions near the outflow boundary. In contrast, the nonloral condition is in excellent agreement with the modal series in this region. 'The discrepancy in the attenuation predictions obtained with the other two boundary conditions was not eliminated by applying the boundary conditions closer to the source. To the contrary, the discrepancy on a percentage basis increased when the boundary was moved closer to the source. Purther, predictions with the nonlocal condition were equally accurate when the boundary condition application point was moved close to the source.

Figure 10 shows the predictions at $1,000 \mathrm{H} z$ for the same source and duct length as figure 9. The boundary condition of lingquist and Majda gave poor predictions and this curve is not shown. The two remaining boundary conditions give accurate predictions, although the nonlocal condition is closer to the inodal series results. Figure 11 shows predictions when the frequency is increased to $5,000 / / z$ and all boundary condition curves included. Note that the liner performs poorly at this frequency giving little attenuation. All boundary conditions give good predictions at this frequency. Note that the curve for the nonlocal condition and the modal series solution are identical.

It should be noted that in [7], results at, a frequency of $5,000 \mathrm{~Hz}$ could not be accurately predicted using the nonlocal boundary condition. Further, it was speculated that the poor prediction at this frequency was a result of using only 3.4 points per axial wavelength. The banded solver adopled in this paper allows several hundred thousand degrees of freedom to be: incorporated with relative ease. 'Tlie good agreement with the modal series predictions at 5,000 $/ z z$ using the nonlocal boundary condition confirms that this conjecture was true.

'lurbomachincry sources, such as aircraft engine lans, are distributed sources. Such sources contain acoustic energy in many duct modes. Figure 12 compares attenuation pre- 
dictions for the distributed source define by (22) at a frequency of $100 \mathrm{~Hz}$ and for $L=H$. The nonlocal condition is generally the most accurate for this source. Further, the condition of Engquist and Majda gives attenuation predictions closer to the modal series results than the condition of Giles. Figure 13 shows results for the same source when the frequency is increased to 1,000 Hz. The curve generated by the Engquist and Majda condition is not shown, since it led to predictions ten decilsels higher than the modal series results. Both the Giles and the nonlocal condition give nearly the same predictions, although the Giles condition is slightly more accurate in a small region near the end of the duct.

\section{Concluding Remarks}

Several non-reflecting boundary conditions which have potential application to duct acoustics have been evaluated for their effectiveness. Those that met the criteria and were tested are

1. The local boundary condition of Giles.

2. The local highly-absorbing boundary condition of Engquist and Majda.

3. The nonlocal boundary condition of \%orumski, Watson and Ilodge.

The rase of of an infinite two-dimensional duct without flow was used for simplicity. All three boundary condilions however, have extensions to three dimensionality, variable area and wall linings, and flow. The interior solution techuique was a linear finite clement method. All three boundary conditions were tested using the same grid and order of approximation. A band solver has been used to account for the large number of degrees of freedom required for high frequency and long ducts.

The effectiveness of each boundary condilion has been evaluated by comparing predicted attenuation in a softwall duct with analytical results available from modal theory. All three boundary conditions were evaluated for the lowest order mode, a higher order mode, and for a distributed source. Attemuation predictions for several frequencies were evaluated, and the effects of applying each boundary condition close to the source has been investigated.

Results presented here show that the new nonlocal boundary condition of Zorumski, Watson, and llodge gave results consistent witl exact analytical predictions over a broad range of acoustic parameters. 'This boundary condition gave attenuation predictions more accurate than the condilion of Giles and more accurate than the condition of Engquist and Madja over a range of acoustic paramcters. Giles condition however, was competitive at higher frequencies where the liner was not effective. 'The boundary condition of Engquist and Majda gave poor predictions for the range of parameters considered. The accuracy of 
the attenuation predictions on a percentage basis were olserved to decrease with duct length when the Giles or condition of Engquist and Majda were used. However, the accuracy of the attenuation predicted using the nonlocal boundary condition is accurate for short ducts as well. This is an important result, since a substantial reduction in grid points can be obtained by applying the nonlocal condition close to the souncl source. Implementation of the band solver has confirmed that the poor altenuation predictions at 5,000 $/ \mathrm{z}$ in the earlier paper is a result of having too few points per wavelength in the discretization.

\section{References}

\section{References}

[1] Engquist,Bjorn and Majda, Andrew., "Absorbing Boundary Conditions for the Numerical Simulation of Waves," Mathematics of Computations, Vol. 31, p. 629-651, 1977.

[2] Iledstrom, G.W., "Nonreflecting Boundary Conditions for Nonlinear Hyperbolic Systems," Journal of Computational Physics, Vol. 30, p. 222-237, 1979.

[3] Thompson, Kelvin W., "Time Mependent. Boundary Conditions for Hyperbolic Systems," Journal of Computational Physics, Vol. 68, p. I-28, 1987.

[4] Bayless, A. and Turkel,E., "Radiation Boundary Conditions for Acoustic and Elastic Wave Calculations," Communications on Pure and Applied Mathematics, Vol. 32, p. $312,1979$.

[5] Ciles, M.B., "Nonreflecting Bonndary Conditions for Euler Fequation Calculations," AIAA Paper 89- 191: (.P, I!989.

[6] Watson, Willie R. and Myers, M.K., "I'ime Drpendent Inflow-Outflow Boundary Conditions for 2-1) Acoustic Systems," AlAA Journal, Vol. 29, no. 9, Sept. 1991 p. 1383 1389.

[7] Zorumski, W.F, Watson, W.IR., and Horlge S.I.., " $\Lambda$ Non-reflecting Boundary Conditions for Duct Acoustics," NASA TMI0909!, April, 1994.

[8] Eversman, W., "Energy l'low Criteria for Acoustic Propagation in Ducts with Flow," Journal of the Acoustical Socirty of America, Vol. 49, No. 6, June 1971. 


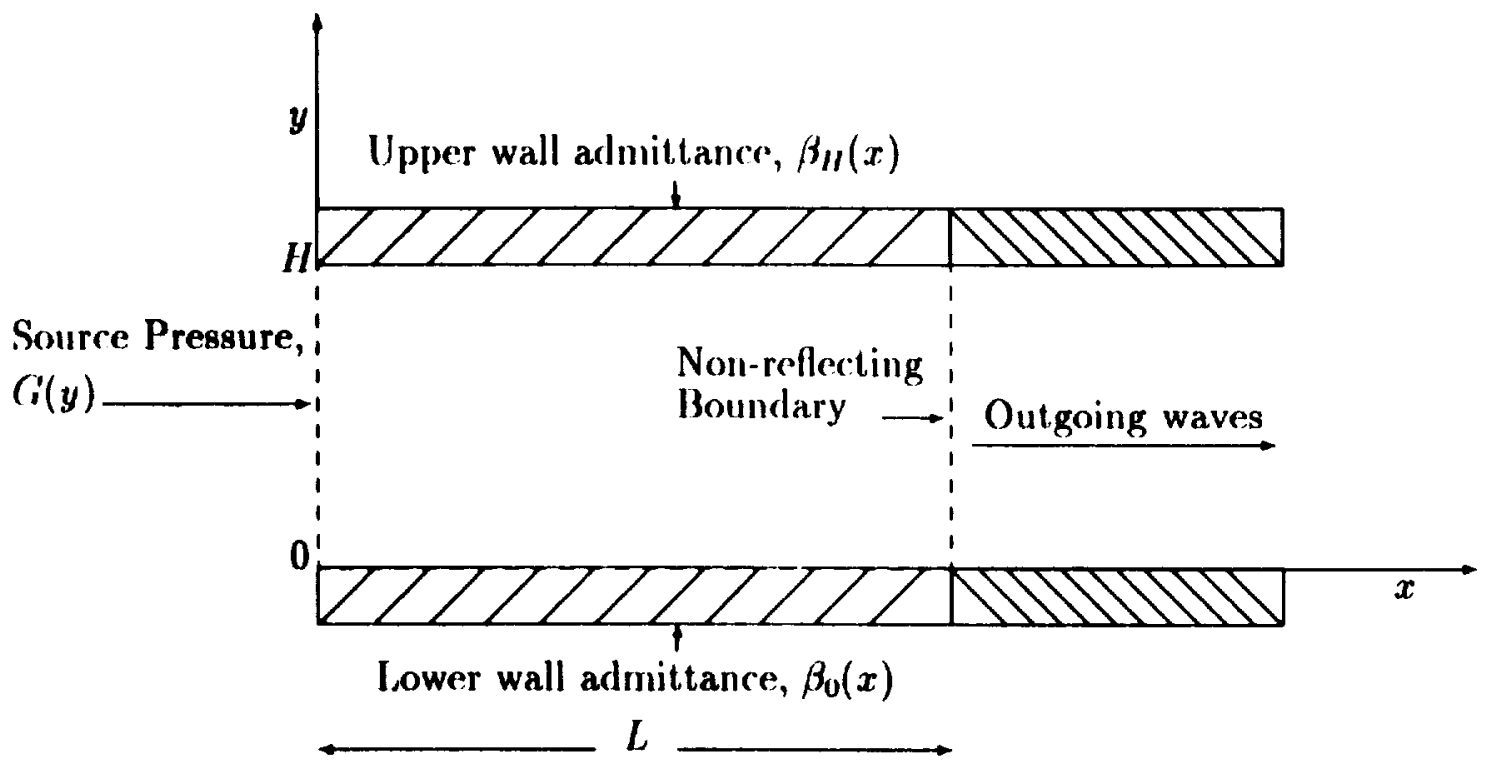

Figure 1: 'I'wo dimensional duct and coordinate system. 


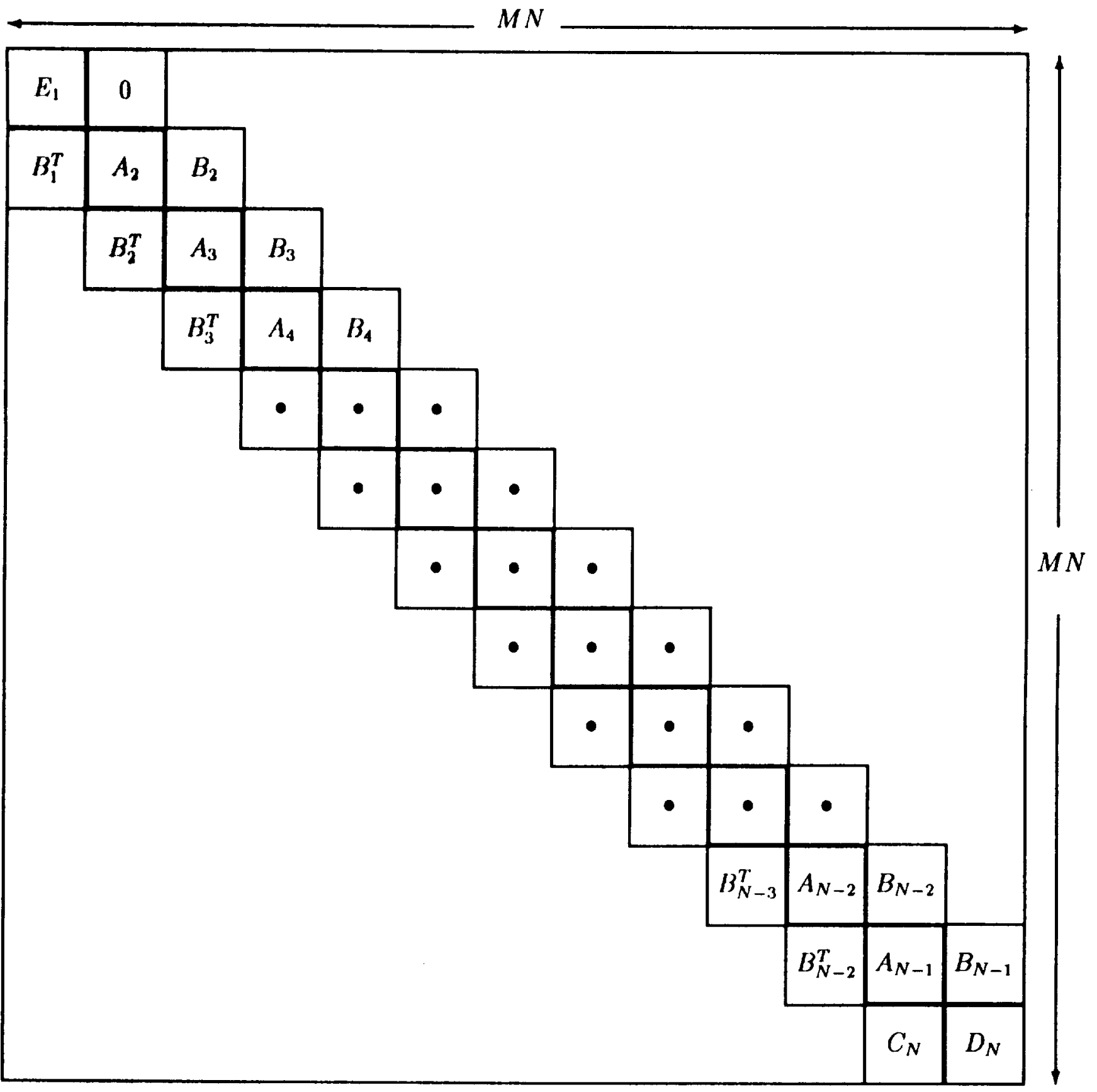

Figure 2: Structure of the global stiffuess matrix, $[\Lambda]$, with minor blocks. 


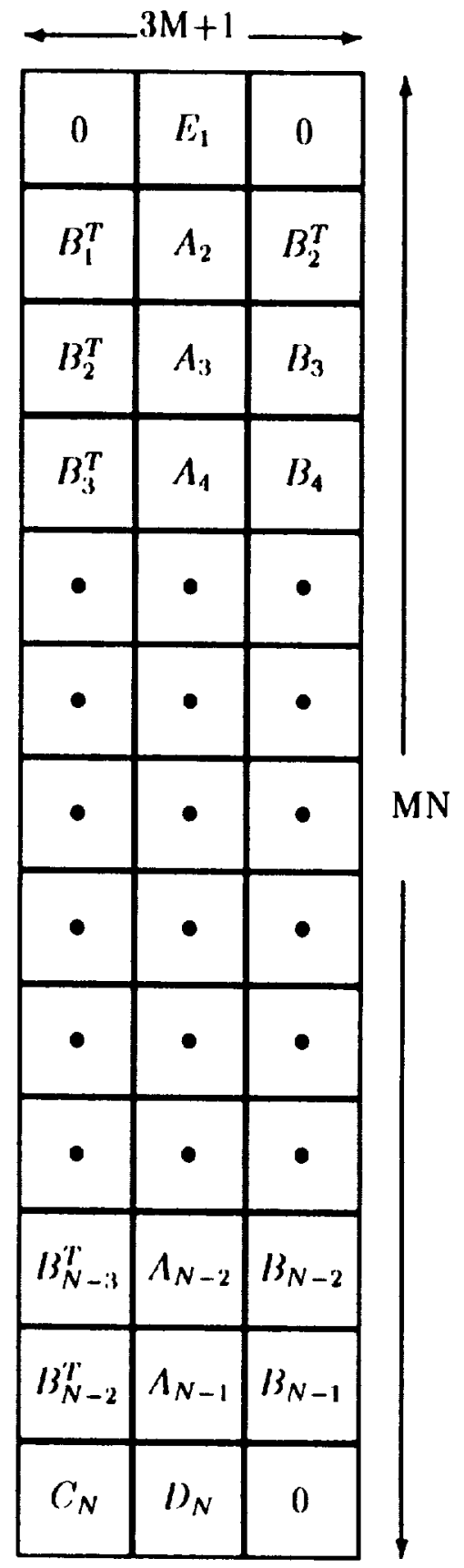

Figure 3: The stored $M N x(3 M+1)$ rectangular coefficient matrix with nonzero coefficients. 


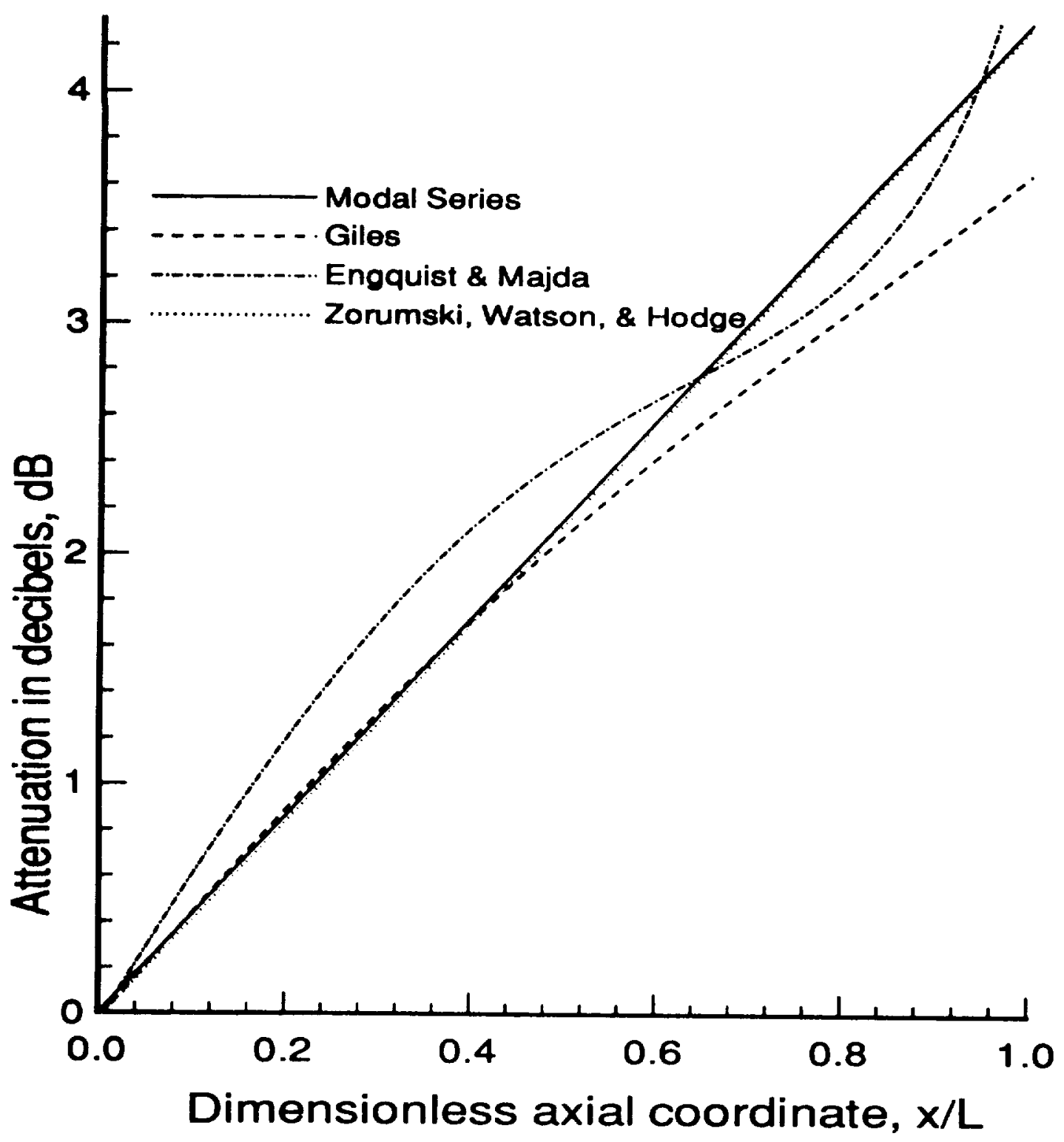

Figure 4: Attemuation comparison for the lowest order mode source in a softwall duct at 100 $I_{z}(\mathrm{l}=\mathrm{II})$. 


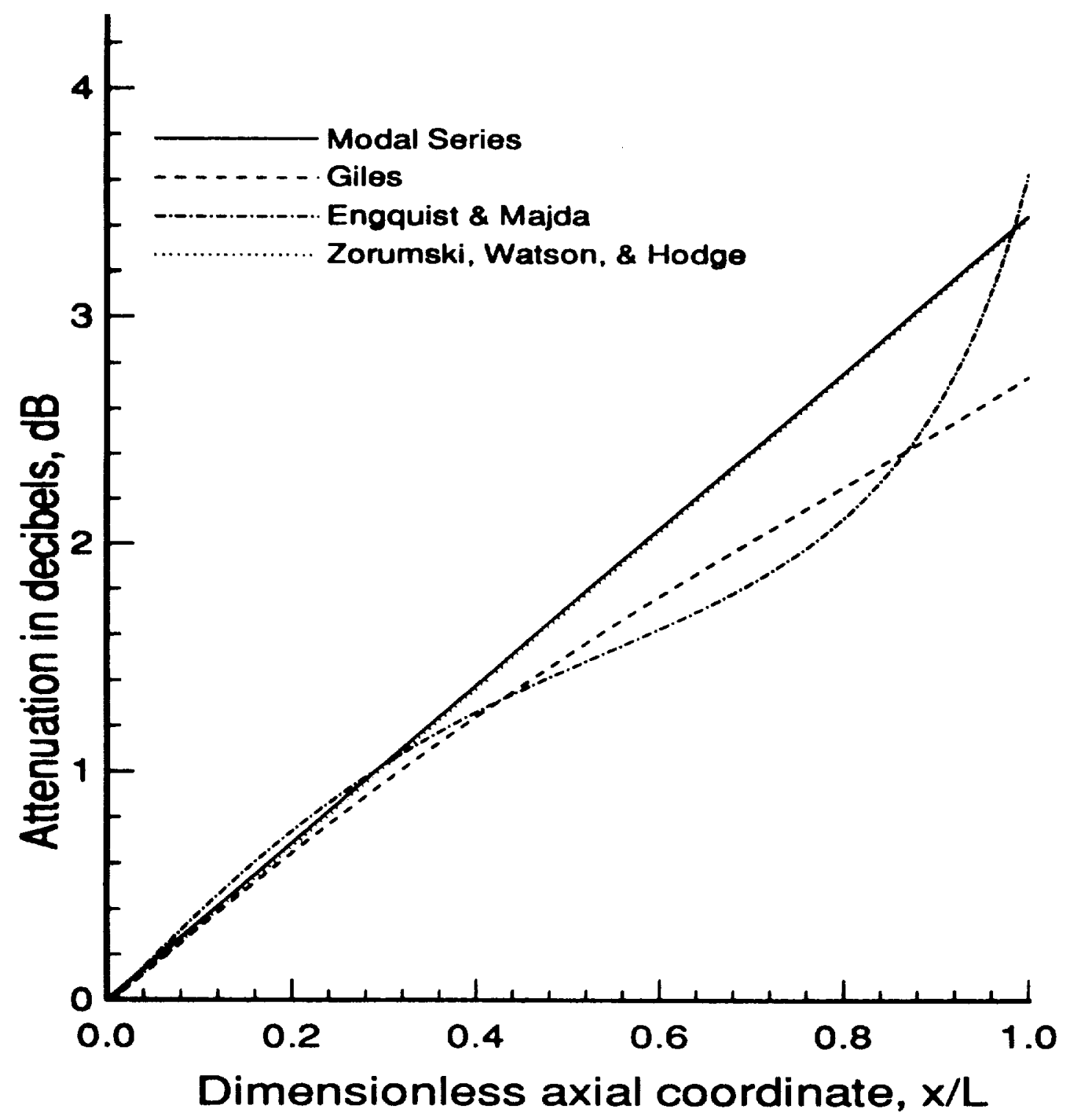

Figure 5: Attenuation comparison for the lowest order mode source in a softwall duct at 100 $H z(I=.8 H)$. 


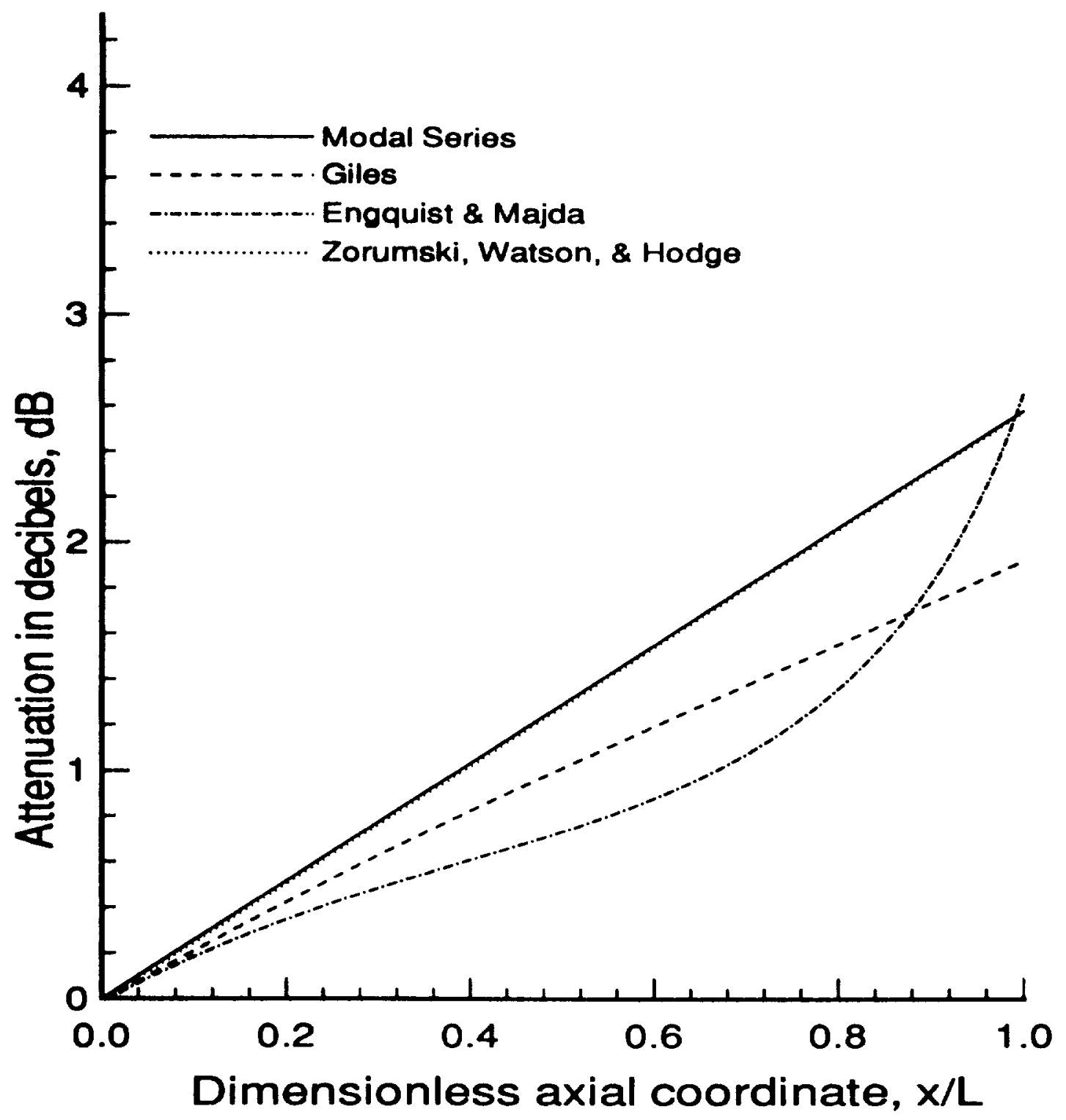

Figure 6: Attenuation comparison for the lowest order mode source in a softwall duct at 100 $H z(L=.6 H)$. 


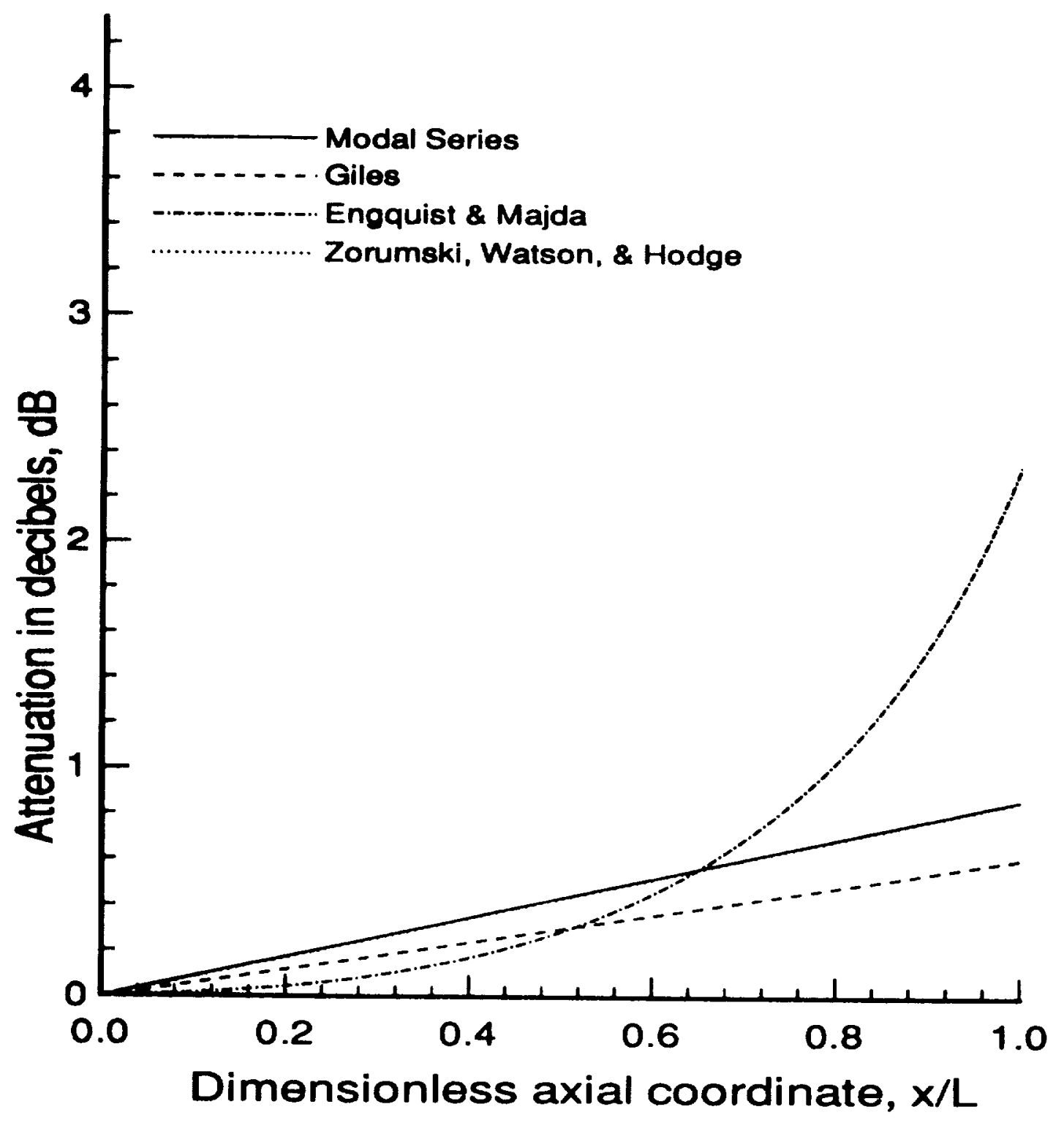

Figure 7: Attenuation comparison for the lowest order morle source in a softwall duct at 100 $\| z(L=.2 H)$. 


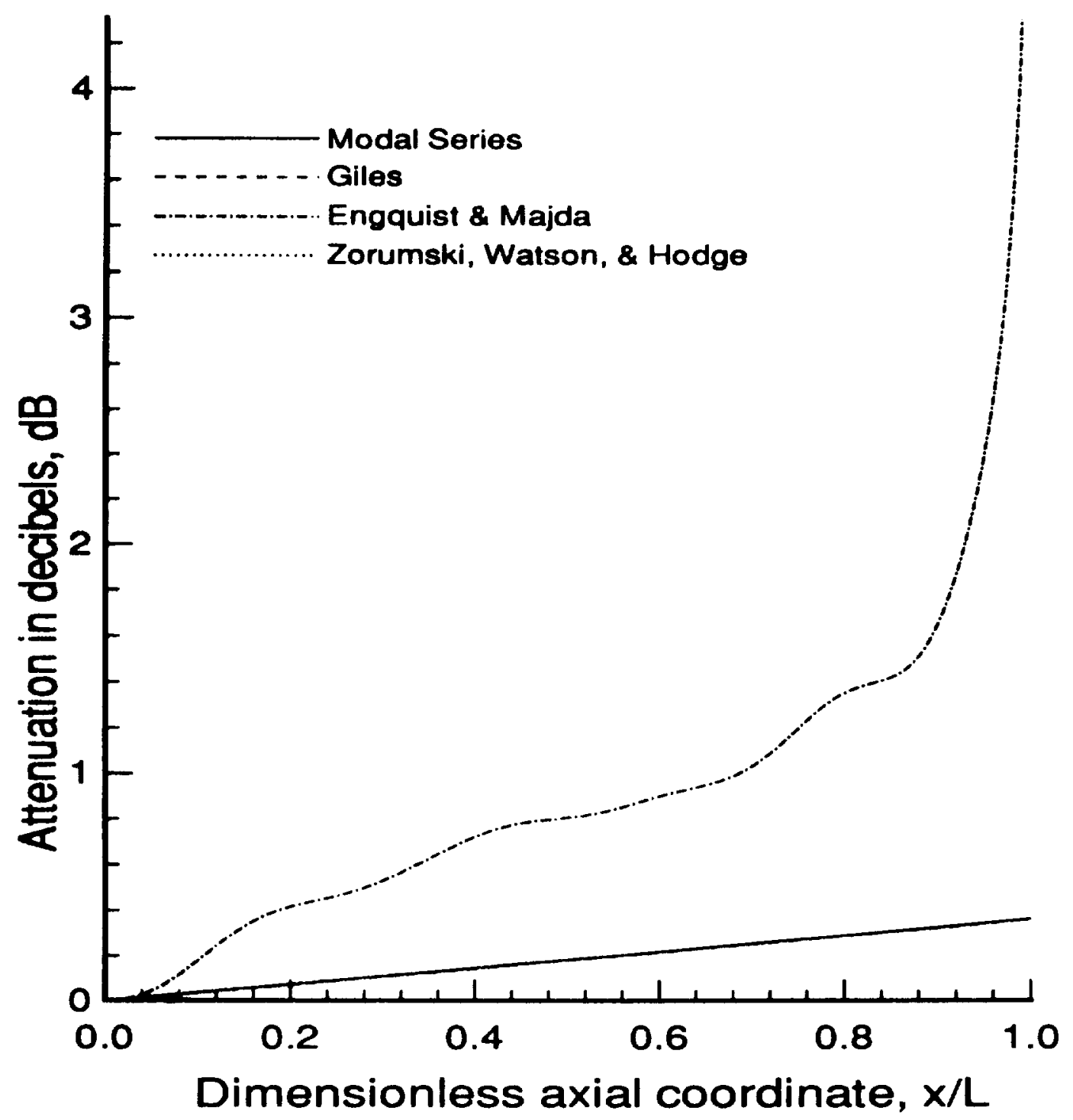

Figure 8: Attenuation comparison for the lowest order mode source in a softwall duct at $1,000 H z(L=I I)$. 


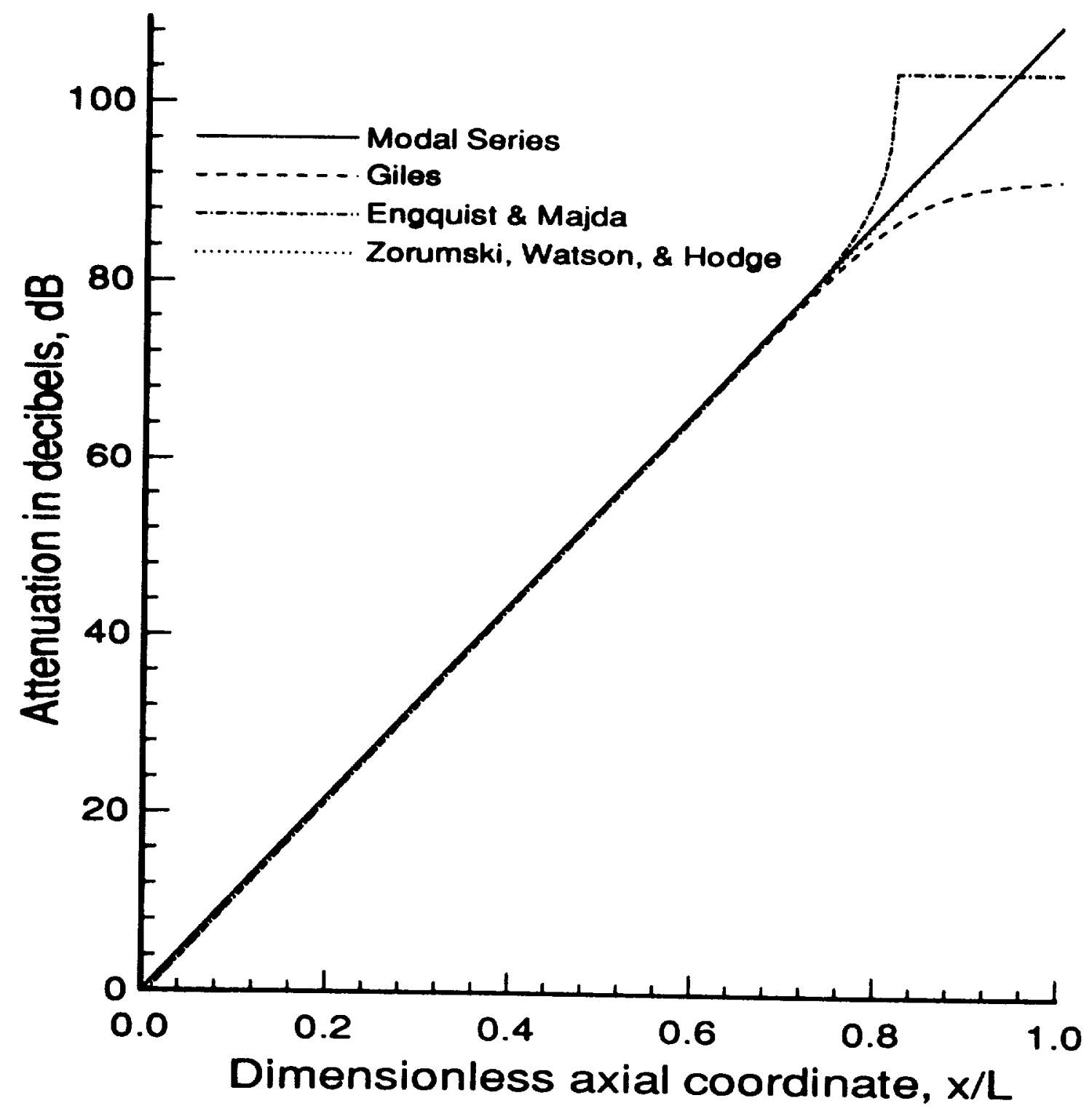

Pigure 9: Attenuation comparison for the fifth order mode source in a softwall duct at 100 $H z(L=H)$. 


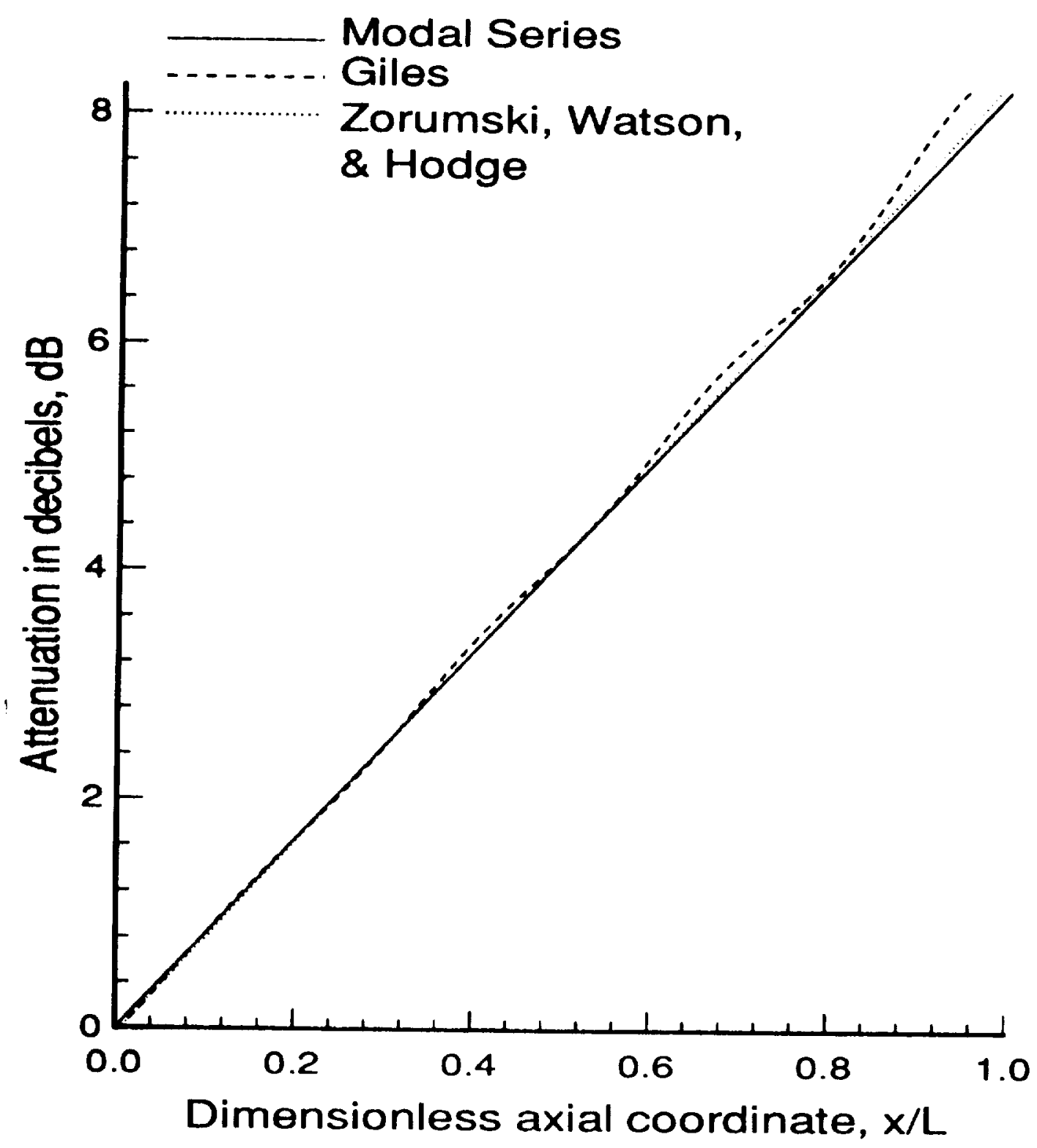

Pigure 10: Altemuation comparison for the lifth order mode source in a softwall duet at 1,000 $H z(L=I I)$. 


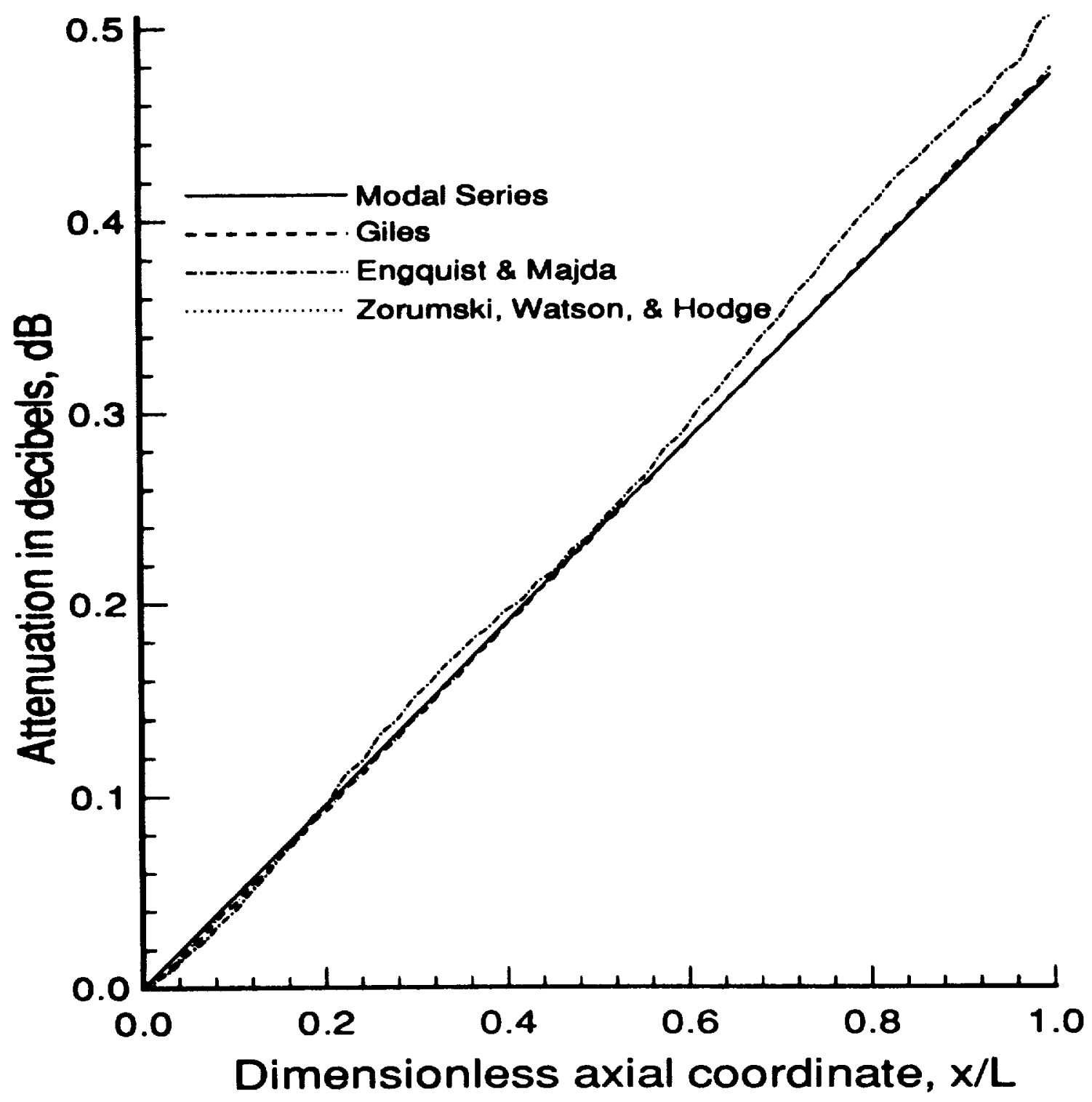

Figure 11: Attemuation comparison for the fifth order mode source in a softwall duct at 5,000 $I I z(L=I I)$. 


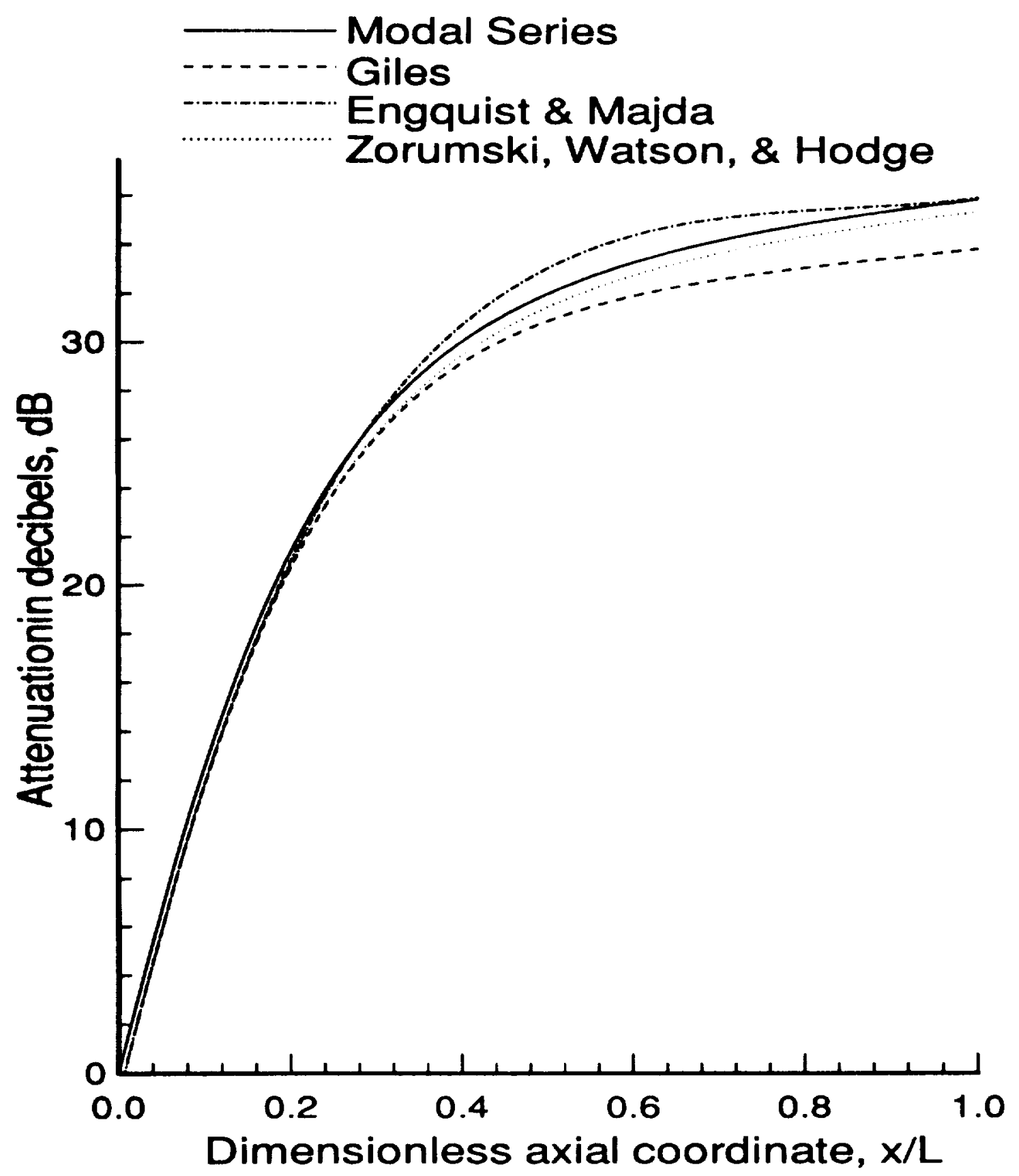

Figure 12: Attenuation comparison for a distributed source in a softwall duct at $100 \mathrm{~Hz}$ $(L=I I)$. 


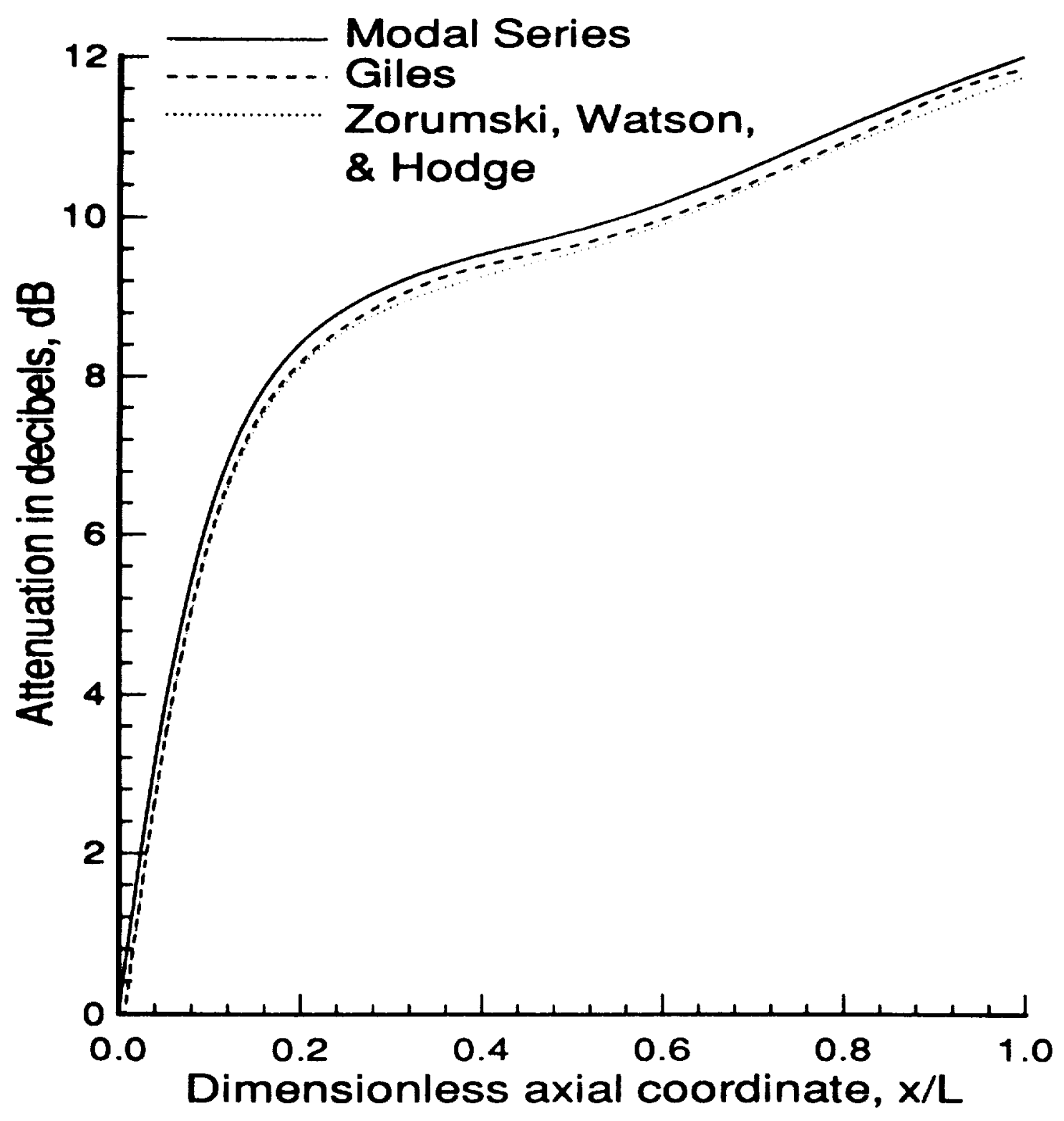

Figure 13: Atlenuation comparison for a distributed source in a softwall duct at $1,000 \mathrm{~Hz}$ $(I=I I)$. 


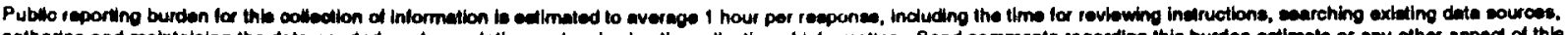

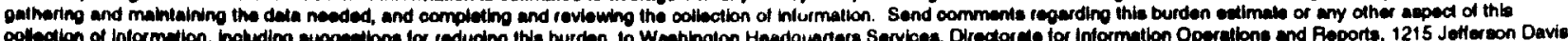

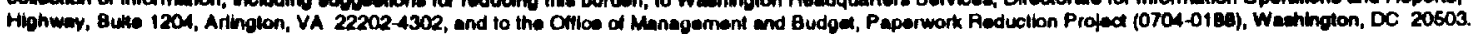

\begin{tabular}{|l|l|l|}
\hline 1. TAEMEY USE OMLY (Leaw blank) & $\begin{array}{l}\text { 2. REPORT DATE } \\
\text { May } 1994\end{array}$ & $\begin{array}{l}\text { 3. AEPOAT TYPE AND DATES COVERED } \\
\text { Technical Memorandum }\end{array}$ \\
\hline
\end{tabular}

Evaluation of Several Non-reflecting Computational Boundary Conditions $\quad$ 538-03-12-01 for Duct Acoustics

C. AUTHOA(8)

Willie R. Watson, William E. Zorumski, and Steve L. Hodge

7. PLAFOAMINO OAQANI2ATION NAME(S) AND ADDAESS(ES)

6. PERFORMING ORGANIZATION

NASA Langley Research Center REPORT NUMBER

Hempton, VA 23681-0001

9. SPONBOAING / MONITOAING AQENCY NAME(S) AND ADDAESS(ES)

National Aeronautics and Space Administration

Washington, DC 20546-0001

SPONSORING/MONITORING AGENCY REPOAT MUMBER

NASA TM-109118

\title{
11. SUPPLEMENTAAY MOTES
}

Watson and Zorumski: Langley Research Center, Hampton, VA

Hodge: Virginia Consortium of Engineering and Science Universities, Hampton, VA

\author{
129. DISTAIBUTIONI AVALABILITY BTATEMENT \\ Unclassified - Unlimited \\ Subject Category 71
}

\section{ABstAACT (Meximum 200 worda)}

Several non-reflecting computational boundary conditions that meet certain criteria and have potential applications to duct acoustics are evaluated for their effectiveness. The same interior solution scheme, grid, and order of approximation are used to evaluate each condition. Sparse matrix solution techniques are applied to solve the matrix equation resulting from the discretization. Modal series solutions for the sound attenuation in an intinite duct are used to evaluate the accuracy of each nonreflecting boundary conditions. The evaluations are performed for sound propagation in a softwall duct, for several sources, sound frequencies, and duct lengths. It is shown that a recently developed nonlocal boundary condition leads to sound attenuation predictions considerably more accurate for short ducts. This leads to a substantial reduction in the number of grid points when compared to other nonreflecting conditions.

\begin{tabular}{|c|c|c|}
\hline \\
\hline \multicolumn{3}{|c|}{$\begin{array}{l}\text { 14. } 8 \text { Uuct Liners; Computational boundary conditions; Non-reflecting boundary } \\
\text { conditions; Finite element method; Helmholiz equation; Sparse marix technique }\end{array}$} \\
\hline $\begin{array}{l}\text { 17. BECUAITY CLASSIFICATION } \\
\text { OF REPOAT } \\
\text { Unclassified }\end{array}$ & $\begin{array}{l}\text { 18. SECUAITY CLASSIFICATION } \\
\text { OF THIS PAGE } \\
\text { Unclassified }\end{array}$ & $\begin{array}{l}\text { 19. SECURITY CLASSIFICATION } \\
\text { OF ABSTRACT }\end{array}$ \\
\hline
\end{tabular}

NSN 7640-01-280-5500
15. NUMBER OF PAGES

25

16. PRICE CODE

A03

20. LIMITATION OF ABSTAACT

Standerd Form 298 (Rov. 2-89) Proworlbed by ANSI Std. Z200.18 